\title{
La intervención de la víctima en el delito de estafa
}

\author{
Sergio Mattos Rázuri ${ }^{1}$ \\ Universidad Científica del Sur
}

\section{RESUMEN}

En este artículo el analiza un caso en el que fácilmente se advierte la relación que existe entre el tipo penal de estafa y la victimodogmática. Específicamente, la problemática que surge en los casos en los que, aparentemente, no estamos frente a un engaño relevante para el derecho penal.

\section{PALABRAS CLAVE}

Estafa, victimodogmática, engaño, derecho penal.

\section{ABSTRACT}

In this article the author tries to establish how criminal nature of fraud is related with victimology. In addition, I will deeply investigate the problem area that appears from cases where we are not dealing with a relevant deceit for criminal law.

\section{KEY WORDS}

Fraud, victimology, deceit, derecho penal. 


\section{Introducción}

Durante el quehacer académico diario se nos presentan problemas o interrogantes que, sin recurrir a herramientas jurídico-dogmáticas, no podrían ser resueltos. Es allí donde nace la motivación para la elaboración del presente trabajo. En tal sentido, en las próximas líneas analizaré un caso en el que se pone de relevancia la relación intrínseca que existe entre el tipo penal de estafa y la victimodogmática; en particular, la problemática que surge en aquellos casos límites en los que, aparentemente, no estamos frente a un engaño relevante para el derecho penal y, por consiguiente, la víctima sería responsable por su acto de disposición y por su propio perjuicio.

\section{Acerca del problema planteado}

Iniciaré el presente trabajo detallando de forma concisa los hechos que originaron el proceso penal que, a su vez, nos servirá para analizar la problemática de la competencia de la víctima en el tipo penal de estafa; a saber:

i. El 2 de enero de 1985 la sociedad conyugal conformada por Juan y María adquirieron un inmueble de tres pisos, ubicado en el distrito de Santiago de Surco. Años después, Juan falleció y, a raíz de ello, el citado inmueble pasó a ser propiedad de la sucesión intestada conformada por María, en calidad de cónyuge supérstite, y de sus tres hijos, Pedro, Miguel y Borja.

ii. Para una mejor comprensión de esta controversia, cabe mencionar que María no tenía ninguna profesión y únicamente se dedicaba a los quehaceres del hogar. Por otro lado, Miguel era un afamado chef, Borja ejercía como periodista y, finalmente, Pedro había obtenido el grado de abogado. Sin embargo, Pedro nunca había tenido éxito en su profesión, lo cual había generado que no tuviera una buena situación económica. Muestra de ello es que, a diferencia de sus hermanos, no tenía una casa propia.

iii. Siendo así, en setiembre de 2000, Pedro le comentó a su madre y hermanos que un par de amigos, también abogados, le habían planteado la posibilidad de abrir un bufete. Su ingreso a aquella sociedad estaba condicionado al aporte económico que debía efectuar, para lo cual necesitaba solicitar un préstamo ante una entidad bancaria.

iv. En tal sentido, Pedro les solicitó que, a fin de «evidenciar» una mayor solvencia económica y calificar como sujeto de crédito en el sistema financiero, le transfiriesen, de manera exclusiva para dichos fines y simuladamente, la propiedad del inmueble descrito anteriormente. A cambio, Pedro le ofreció a cada uno el 3,5\% de las ganancias anuales que él obtuviera en su bufete, lo cual les pareció razonable y atractivo. 
v. Es así que, bajo la premisa de la solicitud planteada por Pedro, tuvo lugar, una reunión dentro del contexto de una relación familiar. Su madre y sus hermanos confiaron en él y aceptaron celebrar un supuesto contrato de compraventa, a fin de «transferirle simuladamente» la propiedad del inmueble en mención. Sin embargo, tal como se señalara anteriormente, la cesión de la propiedad tenía como único objetivo ayudar a Pedro para solicitar préstamos en el sistema financiero, que le permitieran afrontar los gastos del bufete de abogados que pretendía fundar. Cabe destacar que María, Miguel y Borja, en su condición de «parte vendedora», no recibieron suma de dinero alguna de parte de Pedro.

vi. Poco tiempo después, en virtud a un anticipo de legítima, Pedro transfirió la propiedad del inmueble a favor de su hijo, y ahora coprocesado, Alejandro.

vii. Por indicaciones de su padre, Alejandro vendió el inmueble en mención a una pareja de esposos, a cambio del pago de la suma de 500 mil dólares americanos, momento en el cual se materializó el perjuicio económico ocasionado a María, Miguel y Borja, ya que, a raíz de la venta, perdieron la posibilidad de recuperar la propiedad del inmueble y, además, no recibieron ninguna suma de dinero. Evidentemente, Pedro no constituyó ningún bufete o estudio jurídico.

viii.A consecuencia de estos hechos, el Poder Judicial inició un proceso penal en contra de Pedro y Alejandro, por la presunta comisión del delito de estafa, en agravio de María, Miguel y Borja.

Ahora bien, en este punto resulta necesario esbozar una descripción acerca del contenido del delito de estafa, y para ello recurriremos al concepto comúnmente utilizado en la jurisprudencia peruana (Caro John 2007: 239), según la cual este ilícito se configura cuando «el agente, haciendo uso del engaño, astucia, ardid u otra fraudulencia, induce o mantiene en error al sujeto pasivo, con la finalidad de hacer que este en su perjuicio se desprenda de su patrimonio o parte de él y le entregue voluntariamente a aquel en su directo beneficio indebido o de un tercero; delito que llega a consumarse en el mismo momento que el agente obtiene el provecho económico indebido».

Dicho esto, desde mi punto de vista, los hechos que componen el caso objeto de análisis encajan dentro de la descripción del tipo de estafa, el cual presupone en su vertiente objetiva la concurrencia de cuatro hechos vinculados a título de causa-efecto: (i) el sujeto activo ha de desplegar un engaño, que debe resultar idóneo para (ii) producir en el agraviado una situación de error, a consecuencia de la cual (iii) el sujeto engañado lleve a cabo una disposición patrimonial, que (iv) represente un perjuicio económico para el propio disponente o para un tercero (Valle y Quintero 2005, 
y Bramont y García 1998). A continuación, encontrarán una explicación esquemática:

\begin{tabular}{|c|c|c|c|}
\hline Engaño & Error & Disp. patri. & Perjuicio \\
\hline $\begin{array}{c}\text { Pedro le manifestó } \\
\text { a los agravia- } \\
\text { dos que, a fin de } \\
\text { demostrar una } \\
\text { mayor solvencia } \\
\text { económica ante el } \\
\text { sistema financiero, } \\
\text { necesitaba que } \\
\text { le transfirieran la } \\
\text { propiedad. }\end{array}$ & $\begin{array}{l}\text { Los agraviados, } \\
\text { de buena fe, y } \\
\text { convencidos de que } \\
\text { Pedro nunca iba } \\
\text { a disponer del } \\
\text { inmueble como si } \\
\text { fuera propio, } \\
\text { suscribieron la } \\
\text { minuta de com- } \\
\text { praventa. }\end{array}$ & $\begin{array}{l}\text { Al firmar la minuta } \\
\text { y posteriormente } \\
\text { la escritura pública, } \\
\text { los agraviados } \\
\text { dispusieron de su } \\
\text { patrimonio, pues } \\
\text { le transfirieron } \\
\text { la propiedad del } \\
\text { inmueble a Pedro. }\end{array}$ & $\begin{array}{l}\text { Pedro, a través de } \\
\text { su hijo, vendió } \\
\text { el inmueble. } \\
\text { Se benefició } \\
\text { enormente con } \\
\text { dicha operación } \\
\text { y perjudicó a los } \\
\text { agraviados. }\end{array}$ \\
\hline
\end{tabular}

Sin embargo, durante el trámite del proceso penal, Pedro dedujo una excepción de naturaleza de acción y argumentó que los hechos descritos anteriormente no debían ser considerados relevantes para el derecho penal.

Sorprendentemente, el juzgado declaró fundada la excepción deducida por Pedro, y, a consecuencia de ello, ordenó el archivo inmediato del proceso. Es allí donde nace la problemática que pretendo analizar en las próximas páginas, toda vez que, según un magistrado del Poder Judicial, en los hechos materia de instrucción no se observó la concurrencia de todos los elementos objetivos del tipo penal de estafa, específicamente de aquel conocido como engaño bastante. Además, el juzgado consideró que María, Miguel y Borja actuaron negligentemente respecto a la protección de su patrimonio, es decir, no se les puede considerar víctimas del delito de estafa, ya que fueron ellos mismos quienes no adoptaron ninguna medida de cuidado e irresponsablemente dispusieron de un bien inmueble que conformaba su patrimonio.

\section{La competencia de la víctima en el delito de estafa}

Nuestro análisis parte de la premisa de que la estafa es un «delito de relación», es decir, aquel donde el autor no puede alcanzar su propósito criminal sin la «colaboración» de la víctima, que en el caso concreto viene dado por el acto de disposición patrimonial. En este sentido, la profesora Herrera Moreno (1996: 401) refiere que «la participación de la víctima es una condición imprescindible para la consumación del injusto típico, llegándose a afirmar, a tal respecto, que equivale, funcionalmente, a la de un cooperador necesario». Además, la citada autora (2011: 91) considera que en la estafa «la interacción se sustancia mediante una característica 
dinámica ofensor-víctima, que requiere, como presupuesto, una conducta simuladora e inveraz, por parte del infractor, determinante de una correlativa conducta contribuyente de la víctima, quien, movida a engaño, dispondrá de su patrimonio en perjuicio propio o ajeno».

En esta misma línea, Bajo Fernández (2006) afirma que la estafa es un delito de «autolesión», sobre la base de que en estos casos la víctima contraviene el principio de autorresponsabilidad y, a consecuencia de ello, causa su propio detrimento patrimonial. Y, siendo más arriesgado, aunque no por ello faltándole razón, Pawlik (2008: 42) sostiene que la estafa es una autoría mediata tipificada, en la que el autor (el hombre de detrás) utiliza a la víctima (hombre de delante) para lesionar el patrimonio de esta última.

Por tal motivo, basados en criterios victimodogmáticos, un amplio sector de la doctrina penal moderna sostiene que la víctima en el delito de estafa ya no es un mero objeto sobre el cual recae la acción criminal, sino que incluso su comportamiento puede ser el detonante del resultado lesivo para su patrimonio. A consecuencia de ello, no solo el autor de la conducta «engañosa» o «defraudatoria» es candidato a la imputación de responsabilidad por el acto de disposición, sino que también lo puede ser la propia víctima negligente o descuidada (Pastor Muñoz 2003: 68).

Siguiendo esta concepción, cuando pretendamos determinar si una conducta encaja o no dentro del supuesto de hecho del delito de estafa, también deberemos valorar la probable existencia de un ámbito de responsabilidad de la víctima. Cabe recordar que, fuera de especiales relaciones de confianza, el titular de un bien jurídico por sí mismo es competente respecto de las consecuencias dañinas que tienen su origen en la organización defectuosa de su ámbito jurídico (Pawlik 2008: 41). Por lo tanto, salvo en aquellos casos donde la víctima sea considerada «débil» —un niño, un adulto mayor, un deficiente mental o un extranjero que no comprende el idioma-, los engaños burdos, como la venta de «auténticos» relojes Rolex a precios irrisorios, el caso de las «pastillas adelgazantes», etc., no podrán ser objeto de protección a través del tipo de estafa. En este sentido, un engaño que ha sido causa del error puede también ser un engaño no bastante en función del fin de protección de la norma, toda vez que el Estado, a través del tipo de estafa, no protege a las personas insensatas o que, pese a tener la capacidad y posibilidad, no desplegaron la diligencia que les era exigible (Bajo Fernández 2006). Lo antes reseñado nos lleva a una primera conclusión: no toda persona víctima de un engaño que acarree un desmedro patrimonial deberá ser considerada víctima de un delito de estafa.

Cabe resaltar que la jurisprudencia peruana (Rojas Vargas 2012: 627) se ha adherido a los criterios antes esbozados; a saber: 
Debe entenderse al engaño como medio capaz de viciar el consentimiento de un tercero por deformación de la realidad, induciendo a creer y tener por cierto lo que no lo es, con abuso de la confianza que la víctima de buena fe deposita en el autor. Sin embargo, para los fines públicos de punición, la doctrina penal autorizada ha dejado por sentado la necesidad de que el engaño revista de cierta trascendencia objetiva para producir el error causal en la víctima - principio de idoneidad-; así, Conde-Pumpido destaca que el engaño penal debe revestir características propias que lo distingan de una simple mentira, pues considera al engaño como la maniobra fraudulenta que lleva a cabo el autor, que, sin duda, revela mayor peligrosidad, dado que supone la existencia de premeditación y preordenación de medios. En la misma línea, Serrano Gómez refiere que «hay un límite de engaño socialmente permitido, y solo cuando se sobrepasa ese límite entrará en juego el derecho penal, no pudiendo hacerlo antes por el principio de intervención mínima: no todo engaño resulta protegido por el derecho penal».

Por el contrario, en la jurisprudencia española esta es una cuestión muy debatida hasta hoy. Una clara muestra de ello la encontramos en la Sentencia del Tribunal Supremo 162/2012 (ponente: Conde-Pumpido), en la cual se aprecia un cumulo de críticas en contra de la victimodogmática y del rol que los órganos jurisdiccionales del citado país le otorgan a la víctima del delito de estafa:

i. La victimodogmática comete un error cuando renuncia a la intervención penal a favor de la autotutela, puesto que de esa forma desconoce que los ciudadanos han dejado la violencia punitiva en manos del Poder Judicial para descargarse de sus necesidades defensivas frente a las agresiones tipificadas como delictivas.

ii. A través de la victimodogmática se desplaza la responsabilidad del delito de estafa sobre la conducta de la víctima, y se la culpabiliza injustamente por respetar el principio de confianza y se contribuye a su victimización secundaria, la cual surge de una defectuosa relación establecida entre la víctima y el sistema judicial.

iii. El tipo de estafa no contiene un elemento que obligue a entender que a través de la criminalización de estas conductas solo se debe proteger a las personas especialmente perspicaces o desconfiadas, y que, como contrapartida, resulte impune con carácter general el aprovechamiento malicioso de la credulidad, la confianza o la buena fe en los ciudadanos.

iv. Finalmente, el principio de confianza que rige como armazón en nuestro ordenamiento jurídico, o de la buena fe negocial, no se encuentra ausente cuando se enjuicia un delito de estafa. Por lo tanto, la ley no hace excepciones a este respecto, y obliga al perjudicado a estar más precavido en este delito que en otros, de forma que la tutela de la víctima tenga diversos niveles de protección. 


\section{El elemento engaño bastante en una estafa cometida en el seno de una relación familiar}

Ahora bien, volviendo al caso materia de análisis y teniendo en cuenta el fundamento por el cual el juzgado declaró fundada la excepción de naturaleza de acción deducida por Pedro, el núcleo de la discusión radica en qué debemos entender por «engaño bastante». En estricto, el «engaño» puede definirse no como una simple mentira, sino como la discrepancia que existe entre la manifestación del autor y la realidad (Pastor Muñoz 2004: 265). A ello debemos agregar que en el ámbito de la estafa, el «engaño típico» deberá ser entendido como la infracción a un deber de veracidad, y dicho quebrantamiento determinará la responsabilidad del autor por el acto de disposición de la víctima (Pastor Muñoz 2004: 283).

Bajo esta premisa, resulta necesario preguntarnos cuándo el engaño desplegado por el autor es «bastante» para producir un error en la víctima. Es así que, en palabras de la profesora Pastor Muñoz (2006: 214), para determinar la idoneidad del engaño debemos utilizar un criterio objetivo-subjetivo compuesto por dos elementos: i) debe analizarse si el engaño tiene la capacidad de conducir a error a una persona de mediana perspicacia y diligencia, motivo por el cual no constituye engaño típico una mentira burda; y ii) debe valorarse si el engaño es idóneo para conducir a error al destinatario concreto, teniendo en cuenta las características peculiares de este sujeto.

Continuando con la doctrina española, en el mismo sentido se pronuncia Conde-Pumpido (1997: 48-49) cuando dice: «la condición de bastante de un engaño, esto es, su relevancia penal, ha de medirse no objetivamente, sino con un criterio mixto objetivo y subjetivo, esto es, valorando la trascendencia del engaño por su modo de manifestarse y la forma que adopten en función de las circunstancias fácticas y personales del caso y víctima concretos, de modo que sea admisible que por tales circunstancias el engaño fuera creíble para el sujeto pasivo». De igual forma, Valle y Quintero (2005: 644) consideran que: «el juicio de adecuación normativo sobre la conducta deberá tener en cuenta las reales y concretas circunstancias del sujeto pasivo conocidas o reconocibles por el autor. Por tanto, el juicio de previsibilidad objetiva debe nutrirse, también, de las características personales y coyunturales en que se encuentra el sujeto engañado».

Similar opinión manifiesta el jurista peruano Salinas Siccha (2010: 282) al referir que a fin de «calificar la conducta debe adoptarse un criterio objetivo-subjetivo para determinar el engaño, según el cual habrá que considerar si el engaño reviste apariencia de seriedad y realidad suficiente para defraudar a personas de mediana perspicacia y diligencia — parte 
objetiva-y además, en cada caso particular, será preciso tener en cuenta la idoneidad del engaño en función de las condiciones personales del sujeto pasivo — parte subjetiva—».

Cabe resaltar que el Tribunal Supremo español (STS, 28 de enero de 2004) comparte plenamente este criterio y ha establecido que:

La doctrina científica y la jurisprudencia coinciden en afirmar la dificultar para calificar de bastante una conducta engañosa. Suele afirmarse que la calidad del engaño ha de ser examinada conforme a un baremo objetivo y otro subjetivo. El baremo objetivo va referido a un hombre medio y a ciertas exigencias de seriedad y entidad suficiente para afirmarlo. El criterio subjetivo tiene presente las concretas circunstancias del sujeto pasivo. En otras palabras, la cualificación del engaño como bastante pasa por un doble examen, el primero desde la perspectiva de un tercero ajeno a la relación creada, y el segundo desde la óptica del sujeto pasivo, sus concretas circunstancias y situaciones, con observancia siempre de la necesaria exigencia de autodefensa, de manera que se exigirá en el examen del criterio subjetivo una cierta objetivización de la que resulta una seriedad y entidad de la conducta engañosa.

No obstante ello, desde el punto de vista del juzgado, en el caso materia de análisis, los agraviados quebrantaron sus deberes de autoprotección y colocaron su patrimonio en una situación de riesgo. Por lo tanto, la pérdida del inmueble que fuera de su propiedad es un resultado no imputable a Pedro, sino a su propia y desarreglada esfera de organización. Esto es lo que se conoce en doctrina como imputación a la víctima.

Al respecto, debo señalar que no comparto el raciocinio del juzgado, puesto que la imputación a la víctima solo debe operar cuando el incumplimiento o quebrantamiento de los deberes de autoprotección del sujeto pasivo del delito deriven de un rol normativizado, identificable y específico, lo que en el ámbito del injusto de estafa vendría a ser un rol de naturaleza profesional, negocial, bancario, o uno que contenga las mismas características (Herrera Moreno 2011: 95). Siendo así, resulta evidente que, en el caso concreto, ninguno de los agraviados ostentaba un rol especial, razón por la cual no se les podía exigir un nivel de cautela distinto del que en su oportunidad demostraron. Debemos recordar que estamos frente a un acto de disposición patrimonial simulado que fue llevado a cabo por un grupo de personas que forman parte de un mismo núcleo familiar (madre e hijos), y que además estuvo motivado por la solicitud efectuada por Pedro. Por lo tanto, exigirles un nivel de autoprotección mayor nos llevaría al absurdo de afirmar que los agraviados tuvieron la obligación de «leer la mente» de Pedro, de forma tal que pudieran conocer el interés subrepticio 
que él tenía de apropiarse del inmueble en cuestión, para luego venderlo y así poder obtener un cuantioso beneficio económico.

Sobre el particular, Bajo Fernández (2006) refiere que se parte del hecho «de que es obligado atender al ámbito social en que se produce el engaño y el acto de disposición. Cuando el patrimonio del sujeto pasivo está sometido a los peligros inherentes al ámbito de la competencia mercantil, el engaño debe implicar el incremento del riesgo jurídicamente desaprobado, es decir, por encima de lo permitido. Si, por el contrario, el patrimonio corresponde al simple ámbito privado en el que no existen los riesgos del mercado competitivo, basta con que el engaño implique la creación del riesgo». Tomando como base lo dicho por el citado autor, considero que en el caso materia de análisis nos encontramos frente a un negocio jurídico llevado a cabo en un ámbito privado, en el cual los agraviados no pudieron prever los riesgos que usualmente existen en el mercado. Por tal motivo, el riesgo creado por el engaño de Pedro constituye un riesgo normativamente desaprobado, el cual se concretó en el resultado típico, esto es, en el perjuicio patrimonial de las víctimas de la estafa.

Además, otro aspecto que debió valorar el juzgado antes de resolver la excepción deducida por Pedro es que «el mensaje del autor debe interpretarse según el contexto de interacción y no según el significado que haya querido otorgarle el autor o según lo que haya comprendido la víctima» (Pastor Muñoz 2004: 286). En tal sentido, si tenemos en cuenta que los agraviados ya habían tenido ciertas concesiones en el pasado a favor de Pedro, a fin de que este pudiera mejorar su situación económica, lo más sensato era que ante una nueva solicitud por parte de él —tal como ocurrió en el caso concreto-, María, Miguel y Borja aceptaran su requerimiento $\mathrm{y}$, actuando de buena fe, dispusieran una vez más de su patrimonio con la única intención de ayudarlo y de, quizá, obtener algún beneficio económico a consecuencia del porcentaje de ganancias que Pedro les había ofrecido.

Cabe resaltar que constituye un principio socialmente aceptado que las relaciones familiares tan estrechas, como las que existen entre hermanos o entre padres e hijos, se rigen bajo los principios de confianza y de buena fe, en virtud de los cuales existe la expectativa de que jamás una de las partes defraudará patrimonialmente a la otra a fin de obtener un beneficio económico ilícito. Sobre este asunto, resulta interesante la posición de Conde-Pumpido (1997: 51), quien sostiene: «La referencia a la buena fe sirve también para valorar la entidad del engaño. Se trata de sustraer la valoración al arbitrio del sujeto pasivo, en cuanto solo podrá alegar el engaño cuando conforme a las valoraciones ordinarias de las diversas situaciones de la vida cabría esperar que el sujeto activo actuara con veracidad 
y buena fe, de modo que sus alegaciones o afirmaciones debieran tomarse como serias. Se trataría de la confluencia de dos condiciones: por un lado, el que, en la situación concreta, la manifestación engañosa asuma con acento de seriedad una apariencia de credibilidad; por otro, el que la conducta a incriminar desenvuelva su eficacia representativa en una zona gobernada por el principio de buena fe, que obliga al sujeto a la lealtad y veracidad».

En este sentido, considero que resulta verosímil que una persona que necesita capital para emprender un nuevo negocio le solicite a un tercero que lo apoye, a fin de poder acreditar solvencia económica ante el sistema financiero, de forma tal que pueda ser sujeto de crédito. En segundo lugar, si a lo antes señalado le agregamos que entre las partes existía una estrecha relación familiar y que, por tanto, se espera que cualquier comunicación, mensaje o solicitud efectuada por alguno de los sujetos intervinientes esté revestida por el manto de la buena fe, no resulta insensato que María, Miguel y Borja hayan confiado en la versión de Pedro, en el sentido de que él no iba a disponer de la propiedad y que, una vez superada su mala situación económica, iba a restituir el inmueble a la sucesión intestada. Es así que, siguiendo la tesis de Conde-Pumpido (1997: 52), «deben considerarse penalmente relevantes aquellos engaños, cualquiera que sea su mecanismo o forma de manifestarse, que se revisten de credibilidad por desarrollarse en un ámbito que el uso social estima está dominado por la buena fe, de modo que el sujeto pasivo tiene el derecho a confiar en la veracidad de las manifestaciones de la otra parte».

Otro aspecto que sirve de apoyo a nuestra postura se encuentra referido a la duda de la víctima en el delito de estafa. Al respecto, Herrera Moreno (1996: 406) sostiene que, en tanto la víctima dudosa se encuentra obligada a autoprotegerse, la concurrencia de duda rompe la relación de causalidad entre el engaño suficiente y la posterior disposición patrimonial, y puede únicamente apreciar en ese caso una tentativa de estafa, pero no un delito consumado. En tal sentido, una vez más resulta creíble que tanto María, Miguel y Borja confiaran en la propuesta de Pedro y que en ellos no surgiera duda alguna acerca de su solicitud.

Además, desde mi óptica, Pedro, actuando de forma vil y alevosa, se aprovechó de la buena fe y confianza que su madre y hermanos habían depositado en él, y es precisamente este plus de reproche lo que posibilita otorgarle credibilidad a la mise en scène planificada e implementada por el agente delictivo.

En resumen, si el juzgado hubiera valorado tanto las particularidades del caso concreto, así como el contexto en el cual se desarrollaron los hechos materia de instrucción y, en especial, la naturaleza de las víctimas, 
habría advertido que sí nos encontrábamos frente a un engaño idóneo o «bastante», es decir, una inveracidad con la capacidad de generar una situación de error en María, Miguel y Borja. Por consiguiente, considero errónea la valoración del juzgado respecto a que los agraviados debieron intensificar sus medidas de autoprotección, sobre todo si entre ellos y el agente delictivo existía una relación de especial confianza, la cual ulteriormente determinó a las víctimas a no adoptar medidas de autoprotección adicionales.

\section{Conclusiones}

- El tipo de estafa, tanto en el Perú como en España, describe un «delito de relación». Por tal motivo, es utilizado recurrentemente por la ciencia jurídica a fin de explicar los alcances de la victimodogmática.

- Un amplio sector de la doctrina, al cual me adhiero, sostiene que la víctima en el delito de estafa ya no es un mero objeto sobre el que recae la acción criminal, sino que incluso su comportamiento puede ser el detonante del resultado lesivo para su patrimonio.

- En este orden de ideas, el derecho penal no tutela aquellos casos en los que el detrimento patrimonial de la víctima ha sido provocado por un engaño burdo o cuando esta se ha comportado de forma manifiestamente negligente, quebrantando con ello sus deberes de autoprotección.

- A consecuencia de ello, no toda persona víctima de un engaño que acarree un desmedro patrimonial deberá ser considerada víctima de un delito de estafa.

- No existe una posición unánime en la jurisprudencia española acerca de estos temas. Se ha llegado incluso a señalar que a través de la victimodogmática se desplaza la responsabilidad del delito de estafa sobre la conducta de la víctima: se la culpa injustamente por respetar el principio de confianza y se contribuye a su victimización secundaria.

- Respecto al caso objeto de análisis, considero incorrecta la posición adoptada por el juez, toda vez que, si se hubieran valorado tanto las particularidades del caso concreto, así como el contexto en el cual se desarrollaron los hechos materia de instrucción y, en especial, la naturaleza de las víctimas, habría advertido que sí nos encontrábamos frente a un engaño idóneo, es decir, potencialmente apto para generar una situación de error en María, Miguel y Borja. 


\section{REFERENCIAS BIBLIOGRÁFICAS}

BAJO FERNÁNDEZ, Miguel (2006). Los delitos de estafa en el Código Penal. Madrid: Editorial Universitaria Ramón Areces.

BRAMONT-ARIAS TORRES, Luis y GARCÍA CANTIZANO, María (1998). Manual de derecho penal. Parte especial. Lima: San Marcos.

CARO JOHN, José (2007). Diccionario de jurisprudencia penal. Lima: Grijley. CONDE-PUMPIDO, Cándido (1997). Estafas. Valencia: Tirant lo Blanch.

HERRERA MORENO, Myriam (1996). La hora de la víctima. Compendio de victimología. Madrid: Edersa.

(2011). «Estafa, apropiación indebida, defraudación de fluido eléctrico». En Miguel Polaino (editor). Lecciones de derecho penal. Parte especial (tomo II). Madrid: Tecnos.

PASTOR MUÑOZ, Nuria (2003). «El redescubrimiento de la responsabilidad de la víctima en la dogmática de la estafa». En Jesús Silva Sánchez (editor). ¿Libertad económica o fraudes punibles? Madrid: Marcial Pons.

(2004). La determinación del engaño típico en el delito de estafa. Madrid: Marcial Pons.

(2006). «Delitos contra el patrimonio (II)». En Jesús Silva Sánchez (editor). Lecciones de derecho penal. Parte especial. Barcelona: Atelier.

PAWLIK, Michael (2008). «¿Engaño por medio del aprovechamiento de defectos de organización ajenos? Acerca de la distribución de riesgos conforme al 263 StGB en casos de errónea acreditación de cuenta y constelaciones emparentadas». En Anuario de Derecho Penal, vol. 61, nro. 1, pp. 31-52.

ROJAS VARGAS, Fidel (2012). Código Penal. Dos décadas de jurisprudencia (tomo II). Lima: Ara Editores.

SALINAS SICCHA, Ramiro (2010). Delitos contra el patrimonio. Lima: Iustitia y Grijley.

VALLE, José y QUINTERO OLIVARES, Gonzalo (2005). «De las estafas». En Gonzalo Quintero Olivares (coordinador). Comentarios a la parte especial del derecho penal. Navarra: Aranzadi. 